INTER NATIONAL MONETARY FUND

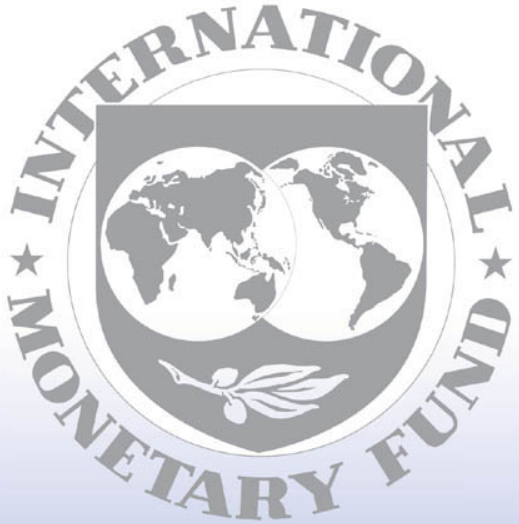

Staff

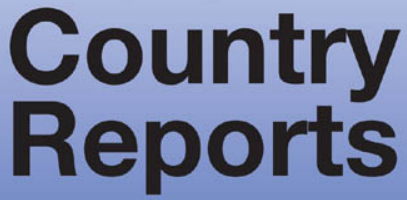




\section{Nepal: Poverty Reduction Strategy Paper Annual Progress Report- Joint Staff Advisory Note}

The attached Joint Staff Advisory Note (JSAN) of the Poverty Reduction Strategy Paper Progress Report for Nepal, prepared jointly by the staffs of the World Bank and the IMF, was distributed with the member country's Poverty Reduction Strategy Paper Annual Progress Report to the Executive Boards of the two institutions. The objective of the JSAN is to provide focused, frank, and constructive feedback to the country on progress in implementing its Poverty Reduction Strategy (PRS).

To assist the IMF in evaluating the publication policy, reader comments are invited and may be sent by e-mail to publicationpolicy@imf.org.

Copies of this report are available to the public from

International Monetary Fund • Publication Services

$70019^{\text {th }}$ Street, N.W. • Washington, D.C. 20431

Telephone: (202) 623-7430 • Telefax: (202) 623-7201

E-mail: publications@imf.org •Internet: http://www.imf.org

\section{International Monetary Fund \\ Washington, D.C.}


This page intentionally left blank

CInternational Monetary Fund. Not for Redistribution 


\section{INTERNATIONAL DEVELOPMENT ASSOCIATION \\ AND \\ INTERNATIONAL MONETARY FUND}

\section{NEPAL}

\section{Joint Staff Advisory Note on the Poverty Reduction Strategy Paper Annual Progress Report}

Prepared by Staffs of the International Development Association (IDA) and the International Monetary Fund (IMF)

Approved by Praful C. Patel (IDA), and Wanda Tseng and Matthew Fisher (IMF)

November 30, 2006

I. Introduction

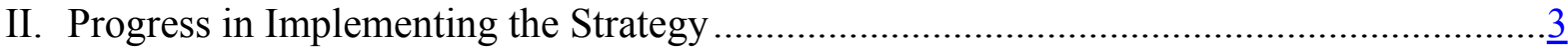

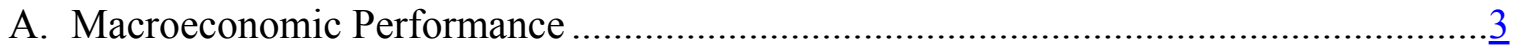

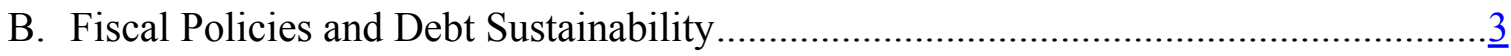

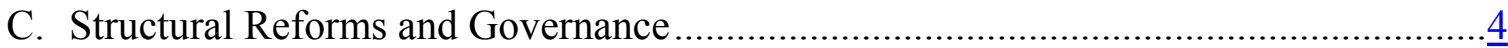

D. Social Sector Development and Targeted Programs ……........................................... $\underline{5}$

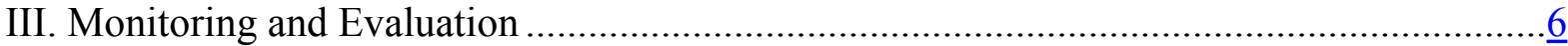




\section{INTRODUCTION}

\section{The third Annual Progress Report (APR) of the Poverty Reduction Strategy} (PRS), which covers fiscal year 2004/05, documents slow economic growth and significant delays in reform implementation due to continued political instability and conflict. ${ }^{1}$ While most macroeconomic indicators were stable, real growth remained low. Beyond 2004/05, political uncertainties continued. There have been significant changes in the political context since April 2006. Peace talks have advanced significantly, reform implementation has progressed in some areas, and economic prospects are expected to improve. With this background, and since the PRS is now in its fifth and last year of implementation, staffs recommend that a review of PRS implementation be undertaken in the next APR. This would help reflect on lessons learned to date and assess the need for change in strategy and programs for effective poverty alleviation, including those related to reconstruction, relief, and rehabilitation. This review would be an input into the three-year plan that is currently being prepared by the government. The exercise could also identify areas for additional analysis, such as debt sustainability and constraints on the level of development spending which has remained low.

2. The APR elaborates on the results of the 2003/04 Nepal Living Standards Survey (NLSS) reported in the previous APR. The NLSS reported a significant decline in poverty incidence from 42 percent in 1995/96 to 31 percent in 2003/04. The APR provides a detailed profile of the poor and poverty dynamics during this period, noting that the decline in poverty was higher in urban than rural areas; poverty declined in all regions except the rural Eastern hills; and inequality increased at the upper end of the income distribution. The APR also documents improvements in basic social services. Staffs welcome the Government of Nepal's (GoN) efforts to update the diagnostics of poverty based on the most recent household survey.

\section{Looking forward, staffs agree with the conclusion that Nepal's growth prospects} depend critically on progress toward peace and PRS implementation. If durable peace can be established and structural reforms are implemented, Nepal could rebound to 3-4 percent growth in 2006/07. This could be achieved through a gradual recovery in the nonagricultural sector and a step up in development spending, with higher aid. Over the medium term, growth could be higher if key structural reforms are implemented, including

\footnotetext{
${ }^{1}$ The PRS, which is Nepal's Tenth Plan covering the period 2002/03-2006/07 (fiscal year begins mid-July), was presented to the Boards of IDA and the IMF in November 2003. The GoN reviewed the implementation of the PRS during 2002/03 and the donor community provided feedback to GoN at the Nepal Development Forum in Kathmandu in May 2004. A second APR, was reviewed in a Joint Staff Advisory Note in November 2005. This APR covers the fiscal year 2004/05 and was finalized by GoN in June 2006 (IMF Country Report No. 06/366 and http://www.npc.gov.np).
} 
tax administration and financial and public sector reforms. Steps are also needed to improve the investment climate and governance.

\section{Progress in Implementing the Strategy}

\section{A. Macroeconomic Performance}

4. The APR documents weaker than targeted growth due to erratic weather, conflict and political instability, which would make the Tenth Plan growth target unachievable. During the first four years of the Tenth Plan (including estimates of 2005/06 which have become available since the preparation of the APR), growth is estimated to have averaged 2.9 percent, below the "lower case" scenario ( 4.3 percent) envisaged in the PRS during the Tenth Plan period. The report rightly notes that the conflict has affected the nonagricultural sector the most, where growth is estimated to have averaged 2.9 percent in 2002/03-2005/06. The sectors most affected by the conflict were trade, industry, tourism, and construction. In the agricultural sector, growth is estimated to have averaged 2.8 percent, the same as the projection under the lower case scenario but lower than the normal case scenario (2.8 percent and 4.1 percent, respectively). Staffs note that other macroeconomic indicators remained stable. Despite supply disruptions in agriculture and higher oil prices, inflation was contained to single digits, anchored by the exchange rate peg to the Indian rupee. International reserves remained adequate supported by continued strong remittances.

\section{B. Fiscal Policies and Debt Sustainability}

5. Fiscal policies remained prudent as revenues broadly covered current expenditures and capital spending was limited to available foreign financing and domestic borrowing. The revenue-to-GDP ratio rose to 131/4 percent of GDP in 2004/05 while expenditures - notably development spending in conflict-affected areas - and aid inflows were lower than budget targets. Overall, these revenue and expenditure trends resulted in lower than planned overall and domestically financed deficits. The APR describes changes in modalities to boost development spending, including through greater local community involvement in projects and rightly concludes that the government's role is changing from that of implementer to facilitator.

6. Looking forward, staffs recommend that the next APR provide a more realistic assessment of fiscal prospects. Further increase in domestic revenues is contingent on tighter administration and base broadening, including through the elimination of VAT exemptions and reducing customs and excise leakages. The next APR, in concert with the budget, could provide estimates of revenue yields of such measures. As regards expenditures, the APR could discuss policy options to overcome implementation capacity constraints in the local level and raise capital spending on a sustainable basis. It could also discuss potential challenges to contain current spending including from contingent liabilities. Staffs also 
recommend that forthcoming APRs elaborate on public debt and fiscal sustainability, including the implications of contingent liabilities from ongoing structural reforms.

\section{Structural Reforms and Governance}

\section{Progress in Agriculture Perspective Plan (APP) implementation has been}

uneven. Although the APR presents agriculture as the highest priority of the PRS, budget allocations to agriculture and irrigation have decreased. Staffs note discrepancies between the APP and the APP Support Program, which has focused on small farmers. Given the role of agriculture in poverty reduction, staffs encourage GoN to further align its programs with the APP and move forward with implementation. The APR also reports some progress in rural infrastructure. Staffs suggest that the next APR fully recognize the importance of maintaining rural roads, especially under the Roads Board.

8. Reporting on infrastructure (other than rural) is weak. The APR reviews progress in the power sector, but does not mention some critical challenges, including increasing power outages. Staffs encourage GoN to report more extensively on progress in the power and road sectors.

9. The APR reports progress in financial sector reforms, but significant challenges remain. Two large commercial banks - Nepal Bank Limited and Rastriya Banijya Bankhave recorded operating profits since 2003/04. The APR documents some progress in the legal and regulatory framework and improvement in Nepal Rastra Bank's supervisory capacity. Although the APR reviews the issue of nonperforming loans (declining but still high), it does not cover the issue of willful defaulters. Staffs encourage the authorities to press on with these reforms especially as recoveries from large willful defaulters are critical to reducing the significant negative net worth of the banks.

\section{The APR outlines some progress in public sector reforms and private sector}

development. The restructuring of state-owned enterprises made limited progress in 2004/05. The APR reports the adoption of a new Labor and Employment Policy and amendments to the Labor Act, but these remain to be confirmed by the Parliament. Staffs recommend clarification of these policies and the Associated Act.

\section{The APR reports deepening of public expenditure management reforms. The} Medium-Term Expenditure Framework (MTEF) now covers the whole budget and transparent criteria for prioritization are used. "Business plans" have been completed for several sectors. These, complemented by Sector-Wide Approaches (SWAps) in the health and education sectors, have contributed to protecting pro-poor spending at a time of pressure for higher salary and security expenditures. To build on these achievements, staffs encourage the GoN to review prioritization criteria (76 percent of projects are classified as priority one) and the impact of "pro-poor" spending on poverty outcomes. Staffs also encourage GoN to increase fiscal transparency and efficiency of spending, including through approval of the 
Procurement Act. Finally, the APR candidly describes low aid absorption and disruptions after February 2005. Staffs support the APR's emphasis on aid effectiveness, through coordination via the MTEF and other Government's systems, and encourage early involvement of donors in APR preparation and budget formulation to help secure external financing for PRS priority areas on a timely basis.

\section{The APR outlines several successful governance initiatives. These include} institutionalizing a Personnel Management database, piloting a performance-based management system, amendments to the Civil Service Act, and passing of a Governance Act. The APR indicates a reduction in transfers, without reporting specific data as was done in previous years. The APR also points out that implementation of these governance reforms remains weak. In the anti-corruption area, the APR reports activities of the Commission for the Investigation of Abuse of Authority (CIAA), which have been somewhat successful. The report recognizes that the CIAA's institutional strength and reach do not allow for effective control of corruption. Staffs encourage GoN to further assess the bottlenecks to the implementation of its governance strategy, notably the role of public awareness campaigns and transparency. The APR also reports on developments in the judicial sector, noting a huge backlog of cases. Staffs encourage implementation of judicial reforms and look forward to a progress report in the next APR.

13. The APR rightly stresses local governance. While progress has been significant in the health and education sectors, decentralization has slowed down since 2002. Staffs welcome the analysis of a key weakness in this area - the different interpretation of decentralization by agencies executing similar programs - and encourage the GoN to develop a clear unified, vision.

\section{Social Sector Development and Targeted Programs}

\section{In education and health, progress toward the PRS objectives has been uneven.}

The planned transfer of the management of schools and basic health facilities to local communities has continued, albeit at a lower pace. In some areas, the APR candidly reports weaknesses, such as poor progress in adult literacy and setbacks in several health indicators (including immunization). With respect to water supply and sanitation, the APR concludes that, despite progress in 2004/05, PRS objectives are unlikely to be achieved given the need to rehabilitate systems. Staffs welcome the candid assessment of the slow down in implementation, which the APR relates notably to political uncertainty, resistance from some groups, security constraints and weak monitoring. Staffs recommend pressing with the reforms envisaged in the PRS. This will require confirming some critical policy decisions (such as transfer of school management to communities) and focusing on implementation (including stronger incentives in the administration and performance management, further reduction in transfers, and donor harmonization). Staffs also suggest that the next APR could document more explicitly the benefits of implementation modalities such as transfer of 
management to local communities. Staffs also recommend acknowledging the role of the private sector in the delivery of health and education services.

\section{The APR reviews progress towards MDGs, noting that Nepal may be able to} attain all of the MDGs except for the goals related to universal primary education and combating HIV/AIDS. It notes that bringing women and the disadvantaged populations (Dalits, Janjatis) into the development mainstream is the key for accelerating progress towards MDGs. While the achievements of Nepal in poverty reduction and improvements in human development indicators are commendable, the diagnostics of the challenges ahead are uneven, with some sections more candid than others. Staffs suggest assessing realistically the likelihood of meeting the PRS objectives with a view to adjust implementation and inform the upcoming plan.

\section{The APR analyzes the impact on disadvantaged groups of several GoN's} programs, but recognizes a decrease in spending for targeted programs. Staffs welcome the analysis of the impact of sector programs (e.g., urban projects) on disadvantaged groups. Staffs also welcome progress made with the Poverty Alleviation Fund and the development of a monitoring mechanism for some targeted programs. Staffs encourage GoN to continue developing the tools to monitor social inclusion and evaluate the impact of public expenditures and policies on various groups within the society.

\section{Monitoring ANd Evaluation}

\section{Progress has been made in finalizing and launching a framework for monitoring} and evaluation. The effort that has been initiated through pilot expenditure tracking experiments in education and health has yielded useful insights. In education, some work was initiated to improve the Education Management Information System. Staffs welcome this very good start and encourage GoN to continue the implementation of these efforts. Staffs also welcome the idea of setting up a central data warehouse as a good start for enabling data availability. The next steps would be to identify the various uses and users of the data and establish an appropriate management structure to ensure timely availability and use of the data. Finally, staffs support the idea of participatory monitoring and suggest designing it to complement other data efforts (for example, the report card can serve as a useful tool for enhancing accountability in delivery of quality services). Staffs suggest outlining the specific areas where such qualitative or participatory data are needed and defining their periodicity.

\section{The APR aptly builds on the work done by the Central Bureau of Statistics in} identifying reasons behind the decline in poverty. Factors such as increases in migration and remittances, improved food availability, and improved employment opportunities are noted together with the decline in fertility (which led to a decline in the dependency ratio). Staffs suggest that other drivers, such as increased wages, improved connectivity, and urbanization, could have been noted for their contribution to the poverty decline. Given its 
impact on poverty, staffs recommend to also acknowledge that agricultural incomes have stagnated, with a move towards high-value crops, horticulture, and livestock rearing just offsetting a decline in incomes from traditional crops among farm households.

19. Finally, while welcoming the comprehensiveness of the APR, staffs suggest reviewing the institutional process of preparing these APRs. This year's APR presents a rich picture of achievements and constraints toward the PRS objectives. However, the APR has a number of data and factual inconsistencies (e.g., coverage of the education sector) and a number of sectoral progress indicators are missing. Staffs urge GoN to assess the process and timing of the next APR's preparation with a view to make this process a component of the annual budget preparation process, hence involving all Government agencies to its finalization and ensuring that its key lessons have an impact on the following budget. Staffs also suggest deepening the efforts toward monitoring and evaluation, with a prioritization toward simple and well-coordinated processes. This would help improve the coordination of donor support and streamline reporting requirements. 